\title{
DIHYDROXYACETONE STUDIES
}

\section{Its Respiratory and Carbohydrate Metabolism in Diabetes Melitus}

\author{
By EDWARD H. MASON
}

(With the Technical Assistance of MISS ELEANOR HILL)

(From the University Clinic, the Royal Victoria Hospital, and the Mcdical Department, McGill University, Montreal)

(Received for publication April 27, 1926)

In the first paper (1) it was shown that in normal persons dihydroxyacetone given by mouth in $\mathbf{2 5}$ or $\mathbf{5 0}$ gram doses caused a more rapid and a greater carbohydrate combustion than the same dose of glucose. The elevation of the total metabolism was more marked after the dihydroxyacetone and there was little if any increment increase in the blood sugar.

In this report similar studies have been applied to cases of diabetes mellitus. The methods employed have been the same. There have been compared in the same cases the respiratory exchange and the blood sugar curves after hke doses of glucose and dihydroxyacetone. Fifteen experiments upon seven cases of diabetes mellitus are reported. In all cases except one the amount of glucose or dihydroxyacetone ingested was 25 grams. In the one exception it was $\mathbf{5 0}$ grams. Comparable experiments after like amounts of glucose and dihydroxyacetone were performed in four instances; cases I, II, III, and IV. In the remaining six experiments dihydroxyacetone alone was given. In case I a three hour control experiment after water alone is included.

THE TYPE OF CASE STUDIED

In order to clarify certain of the experimental data it is necessary to consider the degree of severity of the carbohydrate disturbance in the cases studied. In table 1 are presented the pertinent data on each of the seven cases. 


\section{EXPERIMENTAL DATA}

The experimental data are tabulated in tables 2 and 3 , and in part depicted graphically in figures 1 and 2, respectively. Eight of the comparable experiments after like amounts of glucose or dihydroxyacetone are grouped in table 2 and figure 1 . In table 3 and figure 2 , there are recorded experiments after dihydroxyacetone alone; cases IV, and V, having multiple observations performed at different periods in the treatment of the case.

TABLE 1

Carbohydrate tolerance upon discharge from hospital

\begin{tabular}{|c|c|c|c|c|c|c|}
\hline \multirow{2}{*}{ Case number } & \multirow{2}{*}{ Age } & \multicolumn{2}{|c|}{ Diet } & \multirow{2}{*}{$\begin{array}{l}\text { Blood sugar } \\
\text { fasting }\end{array}$} & \multirow{2}{*}{$\begin{array}{l}\text { Insulin per } \\
\text { day }\end{array}$} & \multirow{2}{*}{$\begin{array}{l}\text { Severity of } \\
\text { case }\end{array}$} \\
\hline & & "G"* & Total calories & & & \\
\hline & years & grams & & per cent & units & \\
\hline I & 42 & 95.8 & 2205 & 0.140 & 24 & Moderate \\
\hline II & 55 & 98.9 & 2011 & 0.122 & 10 & Moderate \\
\hline III & 31 & 112.8 & 2166 & 0.142 & 18 & Moderate \\
\hline IV & 17 & 112.8 & 2166 & 0.125 & 0 & Mild \\
\hline V & 13 & 90.8 & 1898 & 0.166 & 24 & Moderate \\
\hline VI & 57 & 128.6 & 2248 & 0.136 & 0 & Mild \\
\hline VII & 13 & 103.3 & 1729 & 0.121 & 0 & Mild \\
\hline
\end{tabular}

* "g" = glucose yield of diet (Woodyat $\mathrm{t}$ ).

$=$ C.H.O. $+0.58 \mathrm{P}+0.1 \mathrm{~F}$.

\section{The non-protein respiratory quotient}

After 25 or 50 grams of dihydroxyacetone there was a greater increment increase in the non-protein respiratory quotient than after the same amount of glucose (table 2 and figure 1). In all four instances after the dihydroxyacetone the maximum increase in the non-protein respiratory quotient was attained at the end of thirty minutes. The rapidity of elevation after the glucose was not consistent, the maximum non-protein respiratory quotient being attained in from thirty to one hundred and twenty minutes. In these four comparable cases the average maximum increment increase in the non-protein respiratory quotient after glucose was 0.048 , and after dihydroxyacetone it was 0.126. It should be noted that the time interval between the two experiments on the same case was not more than three days. 
In table 3 and figure 2 , are reported seven experiments upon four cases of diabetes mellitus. In each experiment 25 grams of dihydroxyacetone were given. In cases IV and V comparable experiments were performed at intervals with a progressively increasing carbohydrate intake. These results demonstrate clearly that the increment increase of the respiratory quotient is influenced by the glycogen reserve of the body (table 4). If the glycogen reserves are depleted the ingestion of 25 grams of dihydroxyacetone results in very little combustion, but the added carbohydrate is largely stored. In the same case as the diet was progressively increased in its carbohydrate content the ingestion of the same amount of dihydroxyacetone caused a prompt and marked rise in the respiratory quotent. It would appear from table 4 that the maximum increment increase of the respiratory quotient is attained more rapidly when the past diet has contained more carbohydrate. It is to be expected that this point would only be applicable in those cases of diabetes mellitus who have the ability to store glycogen.

In Experiment 14 a respiratory quotient of unity was attained in 30 minutes. This was a mild adult diabetic who was taking a diet containing a total glucose yield of 128 grams. The slight increment increase in the blood sugar confirms the mildness of the diabetes. Experiment 15 was done upon a young girl, aged 13, with mild diabetes, following a period of low carbohydrate intake. At the time of the test the total glucose yield of the diet was 76 grams.

The average maximum increment increase of the non-protein respiratory quotient in the eleven experiments after dihydroxyacetone was 0.138 . The excessively low non-protein respiratory quotients obtained in experiments 5,7 , and 14 , namely $0.642,0.661$, and 0.650 respectively, during the second or third hours may be explained by the storage of carbohydrate derived from protein.

\section{The total metabolism}

In the comparable experiments after glucose and dihydroxyacetone (table 2) the increase of the total heat production over the basal level was more marked after dihydroxyacetone. There was one exception to this finding, case II, experiments 4 and 5, when the increase was 21.3 and 11.4 per cent after glucose and dihydroxyacetone respectively. 


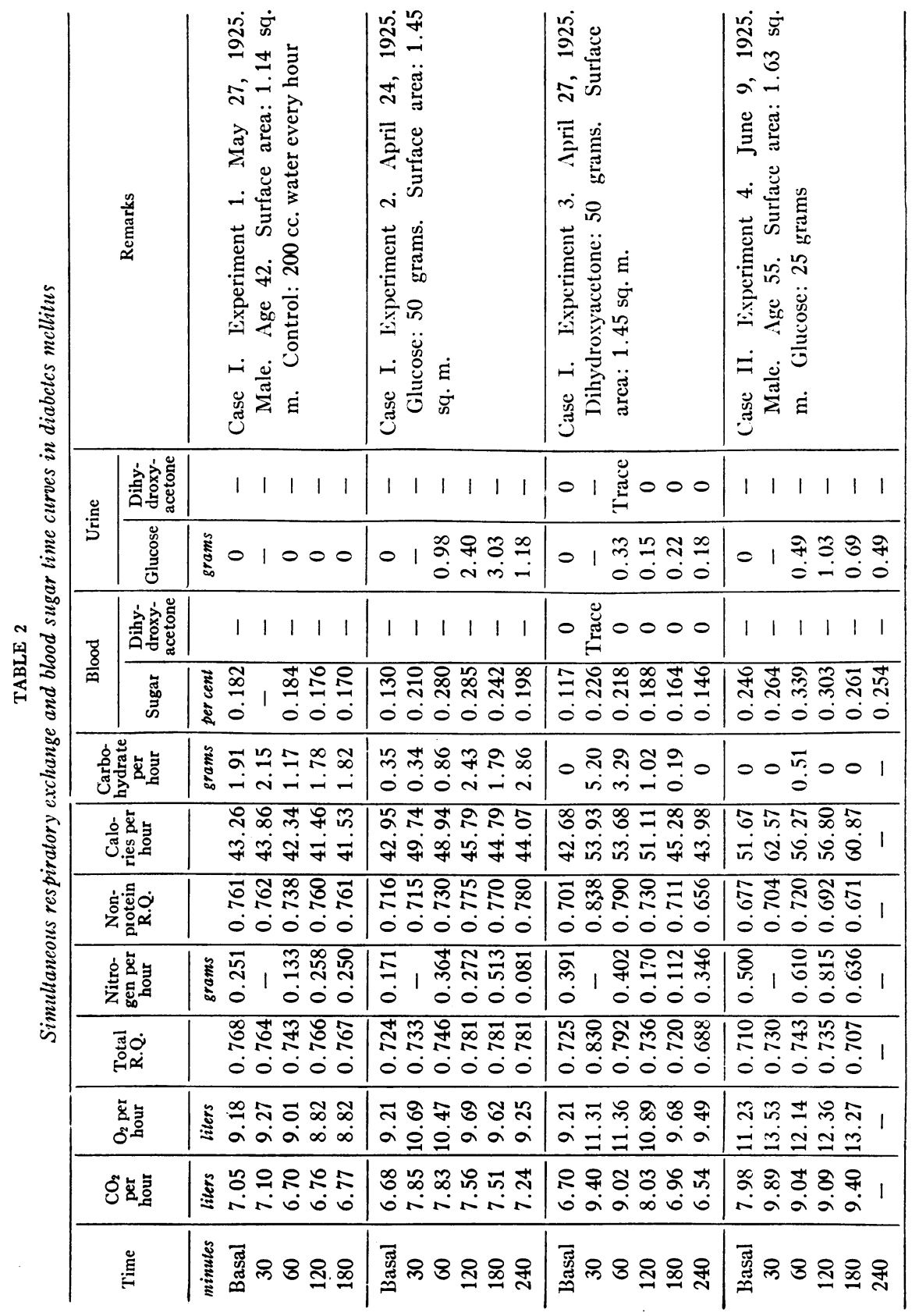




\begin{tabular}{|c|c|c|c|c|}
\hline 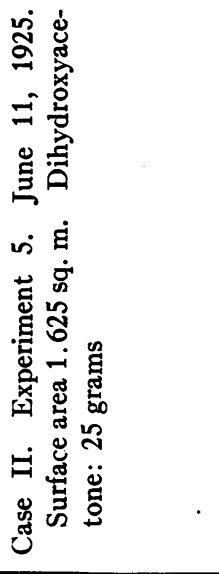 & 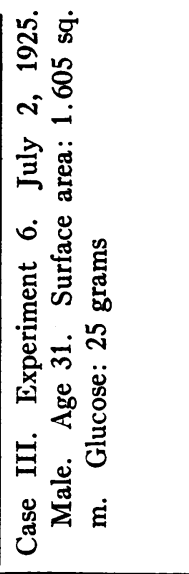 & 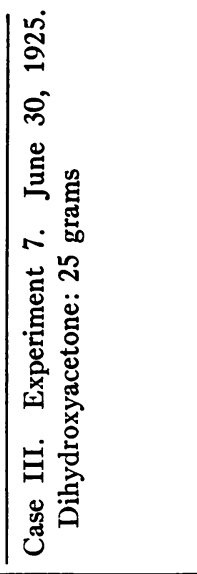 & 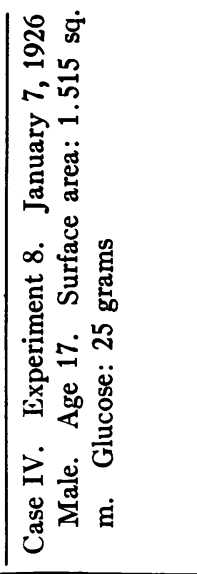 & 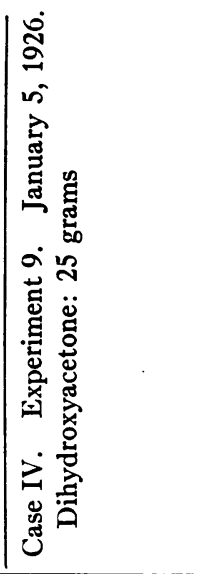 \\
\hline 010001 & $\begin{array}{lllll}1 & 1 & 1 & 1 & 1\end{array}$ & 01000 & $\begin{array}{lllll}1 & 1 & 1 & 1 & 1\end{array}$ & 01000 \\
\hline 010001 & 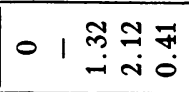 & 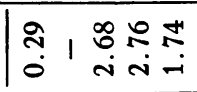 & 01000 & 01000 \\
\hline 000000 & 11111 & 00000 & $\begin{array}{lllll}1 & 1 & 1 & 1 & 1\end{array}$ & 00000 \\
\hline 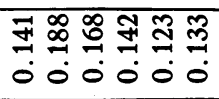 & 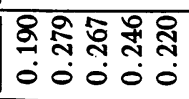 & 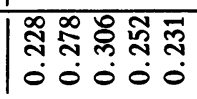 & 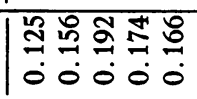 & 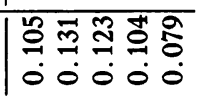 \\
\hline $\begin{array}{l}8.8000 \\
0.000\end{array}$ & 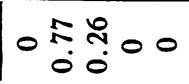 & นึ⿱乛龰⿱ & 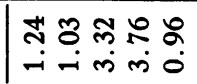 & 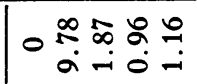 \\
\hline 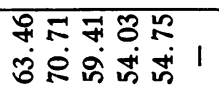 & 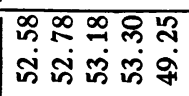 & 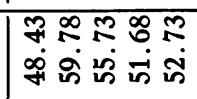 & 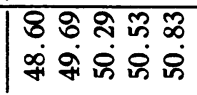 & 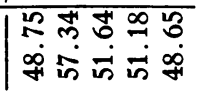 \\
\hline 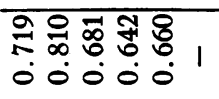 & 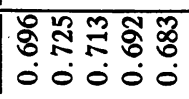 & 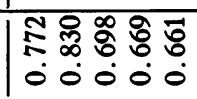 & $\begin{array}{l}\infty \\
0.000 \\
0.020 \\
00000\end{array}$ & 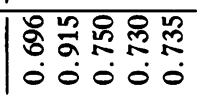 \\
\hline 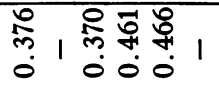 & 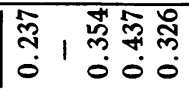 & 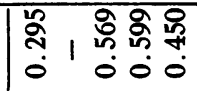 & 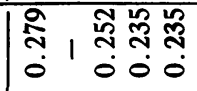 & 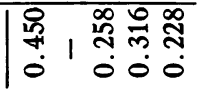 \\
\hline 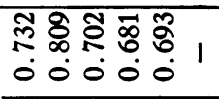 & 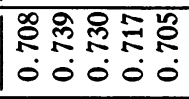 & 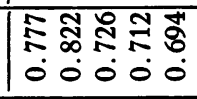 & 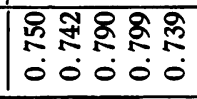 & 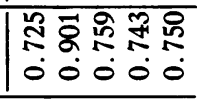 \\
\hline 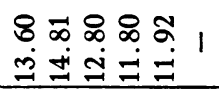 & 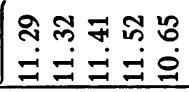 & 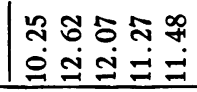 & 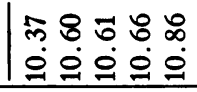 & 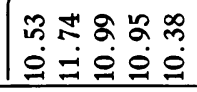 \\
\hline 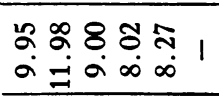 & 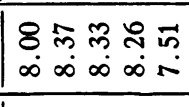 & 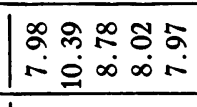 & 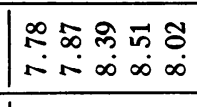 & 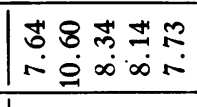 \\
\hline స్త్రై & 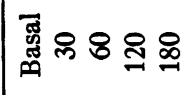 & 㠀 & 哥 & 范 \\
\hline
\end{tabular}




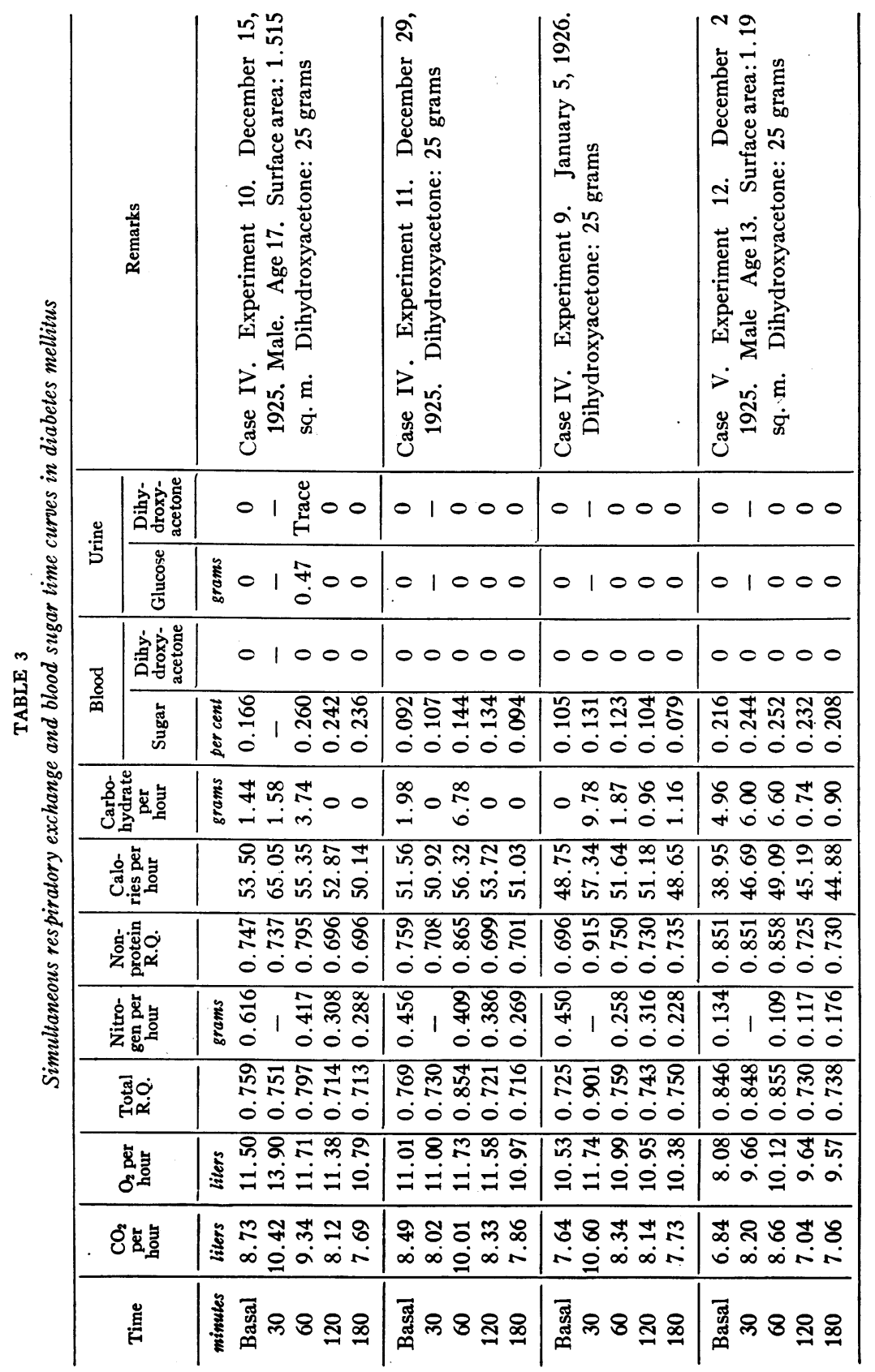




\begin{tabular}{|c|c|c|}
\hline 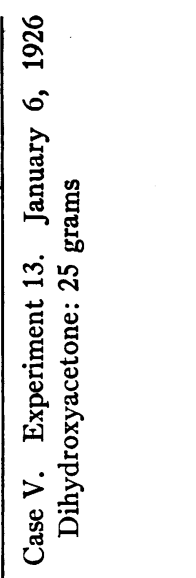 & 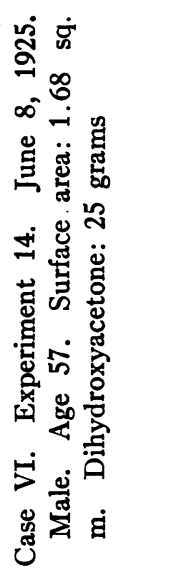 & 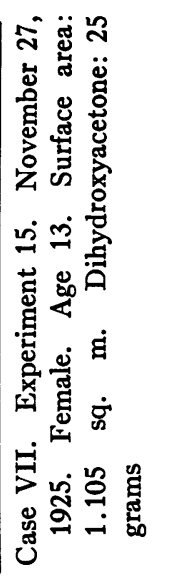 \\
\hline $01+00$ & 01000 & 01000 \\
\hline $01 \stackrel{2}{0} 00$ & 01000 & 01000 \\
\hline 00000 & 00000 & 00000 \\
\hline 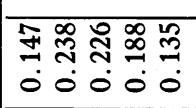 & 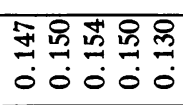 & 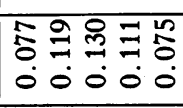 \\
\hline 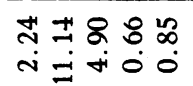 & 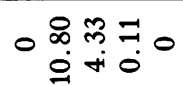 & 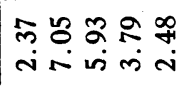 \\
\hline 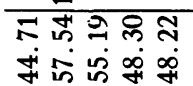 & 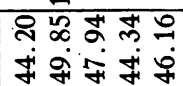 & 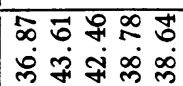 \\
\hline 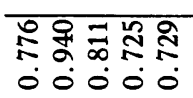 & 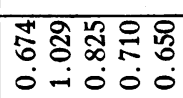 & 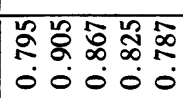 \\
\hline 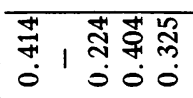 & 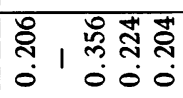 & 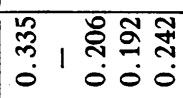 \\
\hline 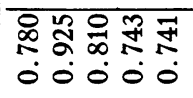 & 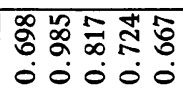 & 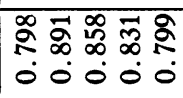 \\
\hline 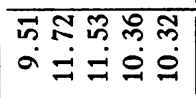 & 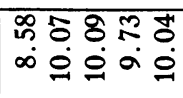 & 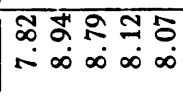 \\
\hline 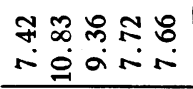 & 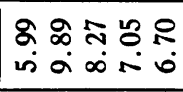 & 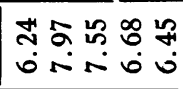 \\
\hline 駱 & శ్లే & 跑 \\
\hline
\end{tabular}


The basal heat production in Experiment 4 was open to some question. However, without excluding this finding the average rise in heat production after glucose was 11.2 per cent, and after dihydroxyacetone 20.0 per cent. In the eleven experiments with dihydroxy

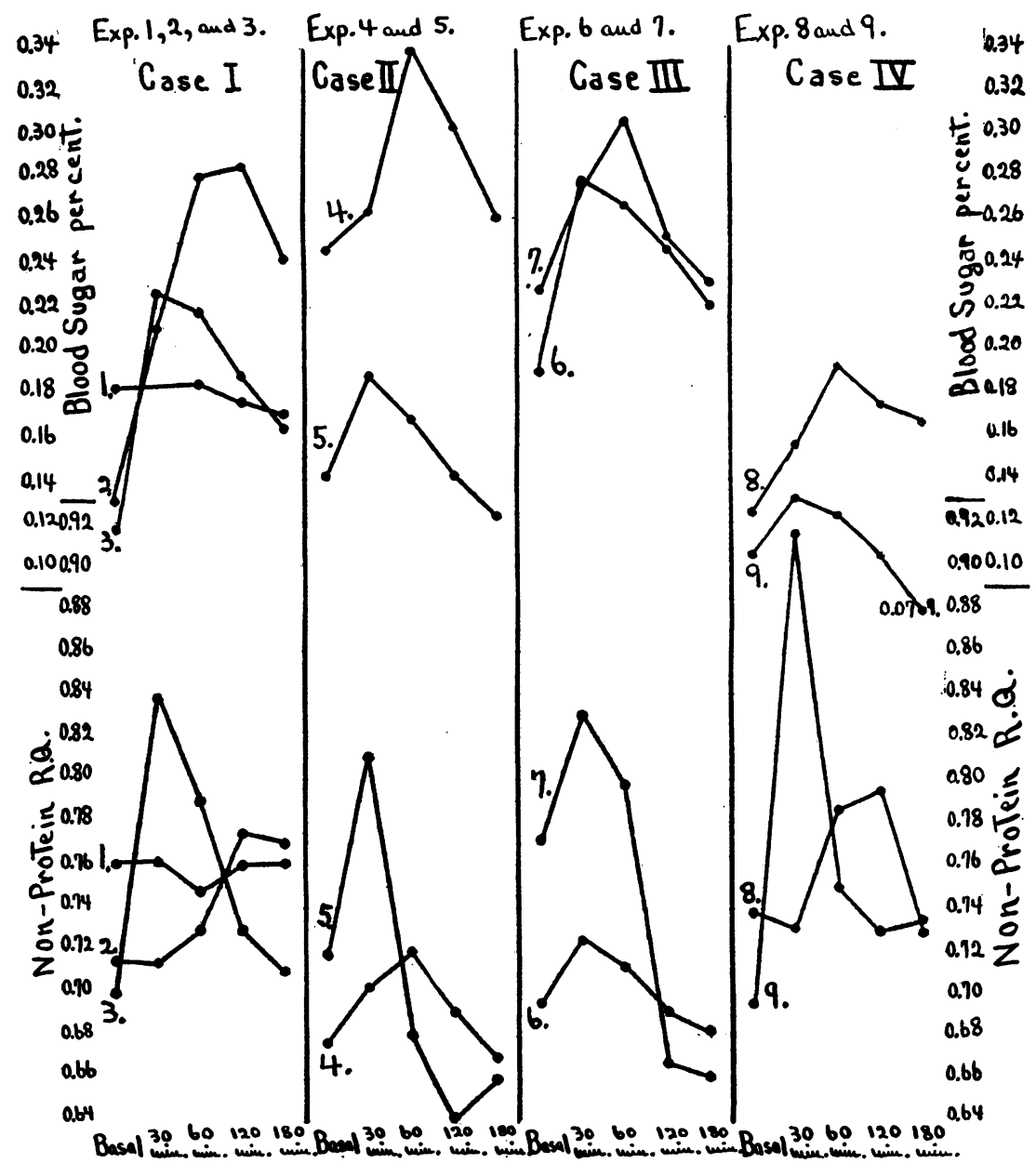

Figure 1. Representing Graphicaliy the Non-Protein Respiratory Quotient and Blood Sugar Time Curves in the Experments Recorded in Table 2

Experiment 1 is a control, $200 \mathrm{cc}$. of water only being given each hour. Experiment 2 is after 50 grams of glucose. Experiments 4, 6, and 8 are after 25 grams of glucose. Experiment 3 is after 50 grams of dihydroxyacetone. Experiments 5, 7, and 9 are after 25 grams of dihydroxyacetone. 
acetone the average increase in heat production over the basal level was 19.4 per cent. . In all except two of these experiments the maximum increase in heat production was attained in thirty minutes,

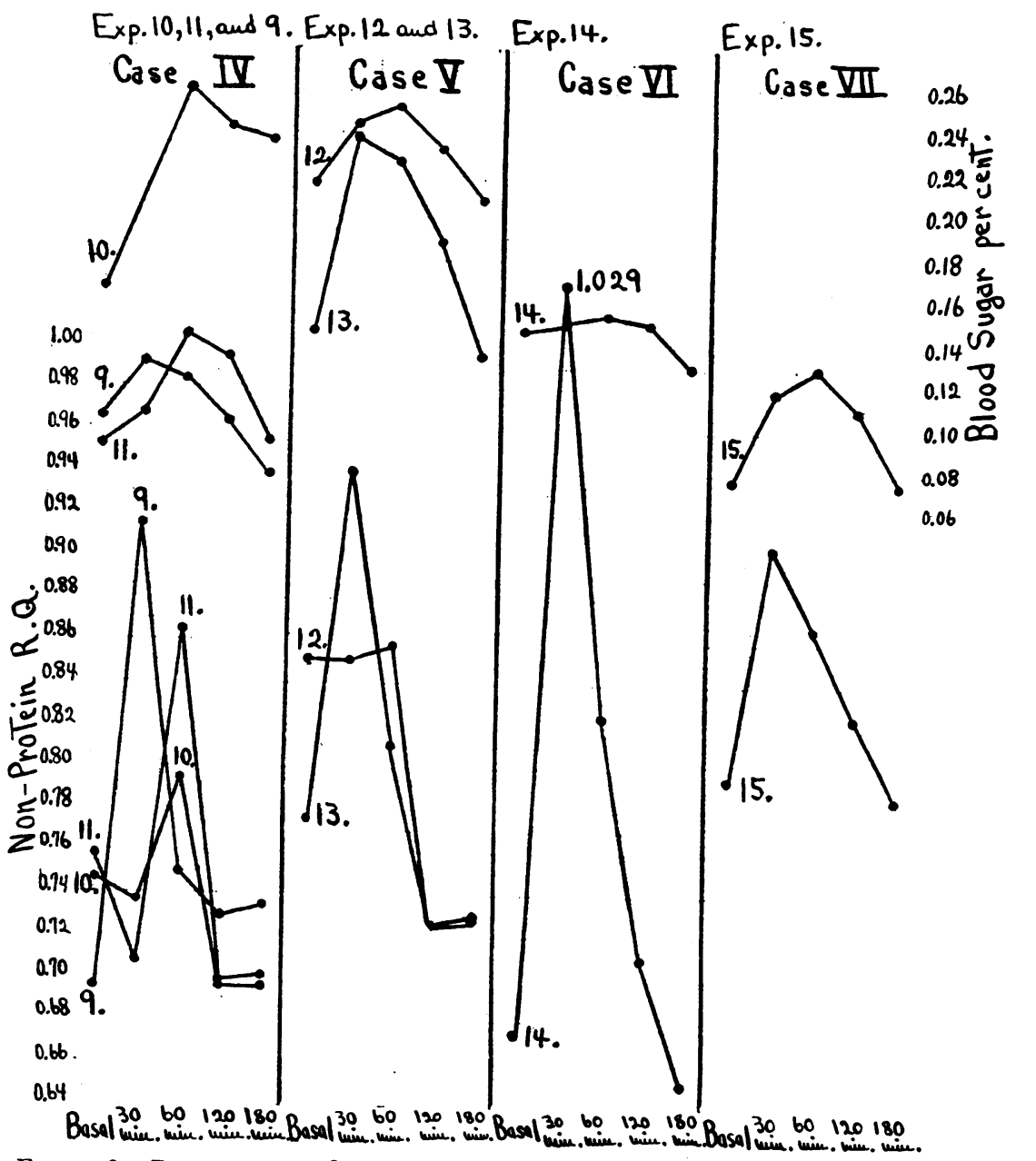

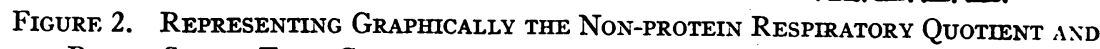
Blood Sugar Tmme Curves in the Expernants Recorded in Table 3

Each experiment is after 25 grams of dihydroxyacetone

while in the two (experiments 11 and 12), it was reached in sixty minutes. 
In the four glucose experiments the maximum total metabolism was reached in thirty minutes in experiments 2 and 4 ; in two hours in experiment 6; and in three hours in experiment 8 . It should be noted that in cases IV and V in which multiple experiments were done with 25 grams of dihydroxyacetone that the rise in heat production did not parallel the rise in the respiratory quotient. This is shown in table 5.

TABLE 4

Infuence of carbohydrate content of diet upon increment increase of respiratory quotient

\begin{tabular}{|c|c|c|c|c|c|}
\hline & \multirow{2}{*}{$\begin{array}{c}\text { Experiment } \\
\text { number }\end{array}$} & \multirow{2}{*}{ "G" of diet } & \multicolumn{2}{|c|}{ Non-protein R.Q. } & \multirow[b]{2}{*}{ Date } \\
\hline & & & $\underset{\substack{\text { increment } \\
\text { increase }}}{\text { Maximum }}$ & $\begin{array}{c}\text { Time } \\
\text { attained }\end{array}$ & \\
\hline \multirow{4}{*}{ IV } & & grams & & minutes & \\
\hline & 10 & 45.7 & 0.048 & 60 & December 15, 1925 \\
\hline & 11 & 96.8 & 0.106 & 60 & December 29, 1925 \\
\hline & 9 & 112.8 & 0.219 & 30 & January 5, 1926 \\
\hline \multirow{2}{*}{ V } & 12 & 69.0 & 0.007 & 60 & December 2, 1925 \\
\hline & 13 & 91.0 & 0.164 & 30 & January 6,1926 \\
\hline
\end{tabular}

"g" of diet = C.H.O. + 0.58 P + 0.1 F (Woodyatt).

TABLE 5

Relation between increase of non-protein R.Q. and total metabolism

\begin{tabular}{|c|c|c|c|}
\hline \multirow{2}{*}{ Case number } & \multirow{2}{*}{ Experiment number } & \multicolumn{2}{|c|}{ Maximum increase } \\
\hline & & Non-protein R.Q. & Total calories \\
\hline \multirow{4}{*}{ IV } & & & per cent \\
\hline & 10 & 0.048 & 21.8 \\
\hline & 11 & 0.106 & 9.0 \\
\hline & 9 & 0.219 & 17.5 \\
\hline \multirow{2}{*}{ V } & 12 & 0.007 & 26.0 \\
\hline & 13 & 0.164 & 28.5 \\
\hline
\end{tabular}

\section{The blood sugar}

After $\mathbf{2 5}$ or $\mathbf{5 0}$ grams of dihydroxyacetone the increment increase of the blood sugar was consistently less than after the same dose of glucose (table 2 and chart 1). In most of the cases the difference was marked. 


\section{Carbohydrate combustion rate}

Inspection of tables 2 and 3 will show the greatly accelerated carbohydrate combustion rate which followed the administration of dihydroxyacetone. In the comparable experiments (table 2) in each instance it greatly exceeded that in the control experiment with glucose. In experiments 9,13 , and 14 , and 15 it temporarily reached practically a normal carbohydrate utilization rate, namely $9.78,11.14$, 10.80 , and 7.05 grams per hour respectively.

\section{Dihydroxyacetone in blood and urine.}

Dihydroxyacetone determined qualitatively was detected in the blood only in experiment 3 . This was in the thirty-minute specimen. In three experiments, nos. 3, 10, and 13 it was found in the urine in a small quantity in the one hour specimen.

\section{SUMMARY AND CONCLUSIONS}

A study of fourteen experiments on seven cases of mild and moderately severe diabetes mellitus would indicate that the respiratory and carbohydrate metabolism of dihydroxyacetone is fundamentally different from that of glucose. For a proper evaluation of the changes in the respiratory quotient after dihydroxyacetone ingestion the carbohydrate content of the previous diet must be known.

The average maximum increment increase of the non-protein respiratory quotient after glucose (4 experiments) was 0.048 , while after dihydroxyacetone (10 experiments) it was 0.130 .

The average increase of total metabolism after glucose (4 experiments) was 11.2 per cent, while after dihydroxyacetone (10 experiments) it was 19.6 per cent.

The blood sugar showed a smaller increment increase after dihydroxyacetone than after glucose.

\section{BIBLIOGRAPHY}

1. Mason, E. H.: Jour. Clin. Invest., this issue. Dihydroxyacetone Studies. I. Its Respiratory and Carbohydrate Metabolism in Normal Men. 